\title{
Finger Print Fractal Dimension as a Supplementary Quantitative Measure Distinguishing Fingerprints and Gender
}

\author{
Sujata S Bhatt ${ }^{1 *}$, Khushbu Vithalani ${ }^{1}$, Jaymin M Patel ${ }^{2}$ and Subhash J Bhatt ${ }^{2}$ \\ ${ }^{1}$ BRD School of Biosciences, Sardar Patel University, India \\ ${ }^{2}$ Department of Mathematics, Sardar Patel University, India
}

Submission: June 16, 2017; Published: July 26, 2017

*Corresponding author: Sujata S Bhatt, BRD School of Biosciences, Sardar Patel University, Vallabh Vidyanagar 388120, India, Email : bhatt.sujata@gmail.com

\begin{abstract}
The fractal dimension is investigated as a supplementary quantitative parameter to help distinguish left hand thumb fingerprints of individuals; and its relationship with gender and blood groups is examined. The study is carried out by computing fractal dimensions of left hand thumb fingerprints of individuals in a random sample followed by appropriate statistical tests like t-test and $\mathrm{z}$-test. It is inferred that there is a significant difference among the values of fractal dimensions among males and females, though they have nearly identical variations; and that the fingerprint patterns whorl and loop as well as the blood groups B and 0 do not exert significant effects on fractal dimensions. By proposing an appropriate statistic, the extent to which the fractal dimensions of fingerprints of any two individual differ is estimated.
\end{abstract}

Keywords: Left hand thumb fingerprint; Fractal curve; Fractal dimension; Gender; ABO blood group

\section{Introduction}

The individuality and the permanence of a fingerprint has been suggested by Galton in 1892. Since then the left hand thumb fingerprint has turned out to be an important biometric identifier. Hence it is interesting to search for quantitative parameters distinguishing different left hand thumb prints, and to understand their physiological significance. We report on an investigation on the fractal dimension of left hand thumb fingerprint as a quantitative measure to help distinguish fingerprints; and on its relationship with gender and ABO blood groups. The epidermal ridges on fingers, commonly known as fingerprints, exhibit mainly three patterns viz. whorls, loops and arches, along with several other complex patterns [1]. These, together with other features of fingerprint ridges like their endings, bifurcations and trifurcations, ridge width, shape, breaks, creases, orientation, pattern, locations and positions of singular points result in a topology believed to make a fingerprint unique for every individual that remains unchanged during life $[1,2]$.

While discussing the individuality problem for fingerprints [3] have noted that the fingerprint matching in biometry based on pattern recognition is not infallible, as it uses only a part of the discriminatory information present in a finger print; and it may be desirable to explore additional complementary representation of a finger print. The overall fractal dimension of a finger print presents itself as a candidate to be an additional supplementary quantifier. In fact [4] have suggested a classification of finger prints with fractal analysis; and have noted that one cannot identify a fingerprint with fractional dimension alone. We examine statistically the extent by which the fractal dimension distinguishes different finger prints.

The fingerprint patterns have also been extensively studied for several aspects like their embryological development and inheritance [2] believed to be responsible for their persistence presumably resulted due to the anatomy and morphogenesis of friction ridge skin. A connection between fingerprint patterns and ABO blood groups has been suggested by [5] whereas a connection between fingerprint print ridge count and gender has been studied by, Rastogi \& Pillai [6] as well as Sanders \& Waters [7]. These motivate us to investigate relationship between the fractal dimension of a fingerprint and each of $\mathrm{ABO}$ blood groups and gender. The possibility of manifestation of complex qualitative biological features in terms of a quantitative parameter like a fractal dimension itself could be exciting. 


\section{Biostatistics and Biometrics Open Access Journal}

\section{Fractals}

The fractal curves and fractal surfaces were discovered by Mandelbrot [8] and have been proposed to describe the geometry of nature and of complex natural phenomena. A fractal pattern exhibits a self similarity in which a part of the whole is similar to the whole; thereby exhibiting a repetition of patterns at different scales. The characteristic features of fractals include self similarity, more or less continuous brokenness (continuity everywhere differentiability nowhere), scale invariance and power law behavior [9]. The fractal dimension of a fractal encodes these features and represents asymptotically the interrelation between the number of repetitions and reductions of an individual fractal object. According to the box counting method, the fractal dimension FD of an object immersed in a two dimensional environment is defined as

$$
F D=\lim _{r \rightarrow 0} \frac{\ln m(r)}{\ln \left(\frac{1}{r}\right)}
$$

where $m(r)$ is the number of boxes in a square grid of size $r$ required to cover the object in question. This comes from the scaling law $\mathrm{m}(\mathrm{r})=\mathrm{C}(1 / \mathrm{r})^{\mathrm{FD}}$ which also exhibits a close formal resemblance to allometric relations. The value of FD is between 1 and 2 for two dimensional images.

\section{Research objectives}

The present note is aimed at reporting the following aspects of our investigation.

1. Does the FD value statistically determine the fingerprint? We propose a simple statistic for this to which our data is subjected to infer an affirmative answer statistically.

2. We investigate correlations of fingerprint FD values with gender and $\mathrm{ABO}$ blood groups. We infer statistically that there is a significant difference in FD values among males and females, though they have nearly identical variations.

\section{Methodology}

Table 1: Shows the data of FD values of left hand thumbprints, gender, fingerprint pattern and blood groups for 70 subjects.

\begin{tabular}{|c|c|c|c|c|c|c|c|c|c|}
\hline No & Gender & FD Value & $\begin{array}{l}\text { Blood } \\
\text { Group }\end{array}$ & Pattern & No & Gender & FD value & $\begin{array}{l}\text { Blood } \\
\text { Group }\end{array}$ & Pattern \\
\hline 1 & $\mathrm{~F}$ & 1.8233 & 0 & Loop & 36 & M & 1.8132 & 0 & Whorl \\
\hline 2 & $\mathrm{~F}$ & 1.7533 & A & Loop & 37 & M & 1.8217 & A & Whorl \\
\hline 3 & F & 1.7659 & B & Loop & 38 & F & 1.824 & 0 & Whorl \\
\hline 4 & $\mathrm{~F}$ & 1.8385 & 0 & Loop & 39 & $\mathrm{~F}$ & 1.8886 & A & Whorl \\
\hline 5 & $\mathrm{~F}$ & 1.8693 & 0 & Loop & 40 & M & 1.8886 & B & Whorl \\
\hline 6 & $\mathrm{~F}$ & 1.8318 & $\mathrm{~B}$ & Loop & 41 & M & 1.9463 & $\mathrm{~B}$ & Whorl \\
\hline 7 & $\mathrm{~F}$ & 1.8458 & 0 & Loop & 42 & M & 1.8399 & $\mathrm{AB}$ & Whorl \\
\hline 8 & $\mathrm{~F}$ & 1.7781 & 0 & Loop & 43 & $\mathrm{~F}$ & 1.8009 & $\mathrm{~B}$ & Whorl \\
\hline 9 & $\mathrm{~F}$ & 1.8296 & $\mathrm{~B}$ & Loop & 44 & M & 1.8009 & B & Whorl \\
\hline 10 & $\mathrm{~F}$ & 1.7501 & $\mathrm{~B}$ & Whorl & 45 & M & 1.8006 & 0 & Whorl \\
\hline 11 & $\mathrm{~F}$ & 1.7815 & $\mathrm{~B}$ & Whorl & 46 & M & 1.7983 & $\mathrm{~B}$ & Whorl \\
\hline 12 & $\mathrm{~F}$ & 1.7747 & 0 & Whorl & 47 & M & 1.8224 & B & Whorl \\
\hline 13 & $\mathrm{~F}$ & 1.8207 & B & Whorl & 48 & $\mathrm{~F}$ & 1.8027 & B & Loop \\
\hline 14 & $\mathrm{~F}$ & 1.8598 & A & Whorl & 49 & M & 1.8458 & 0 & Loop \\
\hline 15 & $\mathrm{~F}$ & 1.779 & 0 & Whorl & 50 & $\mathrm{~F}$ & 1.8448 & A & Loop \\
\hline 16 & $\mathrm{~F}$ & 1.87 & B & Whorl & 51 & $\mathrm{~F}$ & 1.8909 & 0 & Loop \\
\hline 17 & $\mathrm{~F}$ & 1.8807 & B & Whorl & 52 & $\mathrm{~F}$ & 1.7284 & 0 & Loop \\
\hline 18 & M & 1.9036 & $\mathrm{~B}$ & Loop & 53 & $\mathrm{~F}$ & 1.8335 & $\mathrm{~B}$ & Loop \\
\hline 19 & $\mathrm{M}$ & 1.9094 & 0 & Loop & 54 & $\mathrm{M}$ & 1.7725 & 0 & Loop \\
\hline 20 & $\mathrm{M}$ & 1.8148 & A & Loop & 55 & $\mathrm{~F}$ & 1.8714 & 0 & Loop \\
\hline 21 & $\mathrm{M}$ & 1.8966 & A & Loop & 56 & $\mathrm{~F}$ & 1.79 & 0 & Loop \\
\hline 22 & M & 1.8727 & B & Loop & 57 & $\mathrm{~F}$ & 1.945 & B & Loop \\
\hline 23 & $\mathrm{M}$ & 1.8708 & A & Loop & 58 & $\mathrm{~F}$ & 1.848 & B & Loop \\
\hline 24 & $\mathrm{M}$ & 1.8611 & $\mathrm{AB}$ & Loop & 59 & $\mathrm{~F}$ & 1.8956 & 0 & Loop \\
\hline 25 & M & 1.8373 & B & Loop & 60 & $\mathrm{~F}$ & 1.8919 & B & Loop \\
\hline 26 & M & 1.8376 & B & Whorl & 61 & M & 1.8299 & $\mathrm{AB}$ & Arc \\
\hline
\end{tabular}




\section{Biostatistics and Biometrics Open Access Journal}

\begin{tabular}{|c|c|c|c|c|c|c|c|c|c|}
\hline 27 & M & 1.8689 & A & Whorl & 62 & M & 1.9064 & B & Loop \\
\hline 28 & M & 1.8435 & O & Whorl & 63 & M & 1.9615 & A & Whorl \\
\hline 29 & M & 1.8797 & A & Whorl & 64 & M & 1.8995 & AB & Whorl \\
\hline 30 & M & 1.8727 & O & Whorl & 65 & M & 1.8376 & B & Whorl \\
\hline 31 & M & 1.849 & B & Whorl & 66 & M & 1.8089 & O & Loop \\
\hline 32 & M & 1.8855 & B & Whorl & 67 & M & 1.9002 & Arc and \\
loop & Arc and \\
loop & F & 1.8207 & AB \\
\hline 33 & M & 1.8537 & B & Whorl & 68 & F & 1.8105 & B & $\begin{array}{c}\text { Whorl and } \\
\text { arc }\end{array}$ \\
\hline 35 & M & 1.853 & B & Arc & 69 & F & 1.7576 & B & Loop \\
\hline
\end{tabular}

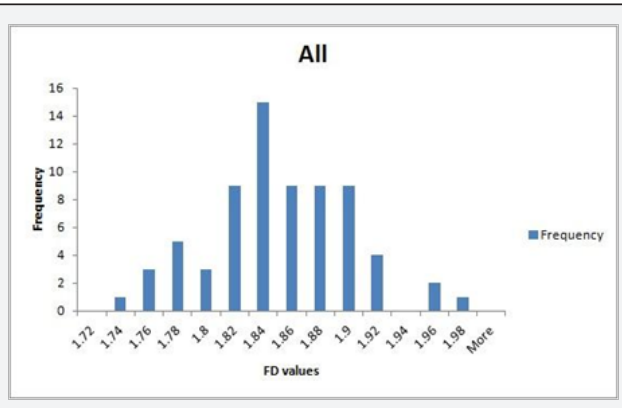

Figure 1: Showing frequency distribution of FD values.

The study was carried out over a period of two months among the students in the university campus as well as individuals from society. Total 70 individuals belonging to the age group 10 to 63 years with 36 males and 34 females have taken part in the study. They have voluntarily participated in the study. Individuals with scars on the thumbs, hand deformity,

Table 2: Values of statistics.

\begin{tabular}{|c|c|c|c|c|c|}
\hline & Mean & Variance & t & F & Chi-Square \\
\hline Male & 1.856 & 0.001846 & 2.652898 & 1.372365 & 1.1256 \\
\hline Female & 1.826371 & 0.002537 & & 1.8662 \\
\hline Loop & 1.840464 & 0.002718 & 0.250675 & & 0.4405 \\
\hline Whorl & 1.843584 & 0.00231 & & \multirow{2}{*}{0.003136} & 0.8849 \\
\hline Blood group B & 1.841413 & 0.002404 & 0.788068 & 0.2318 \\
\hline Blood group 0 & 1.830718 & 0.002396 & & 3.8553 \\
\hline All & 1.841609 & 0.002372 & & & \\
\hline
\end{tabular}

The Chi-square tests show that the FD values follow normal distribution in each of the populations defined by above sub samples. A connection between fingerprint patterns and finger ridge count with human gender has been proposed by many investigators $[2,6,7]$. In the present work, gender related differences in the FD values of left hand thumb prints have been detected (histograms 2a and 2b). The average FD value is found to be higher in male (1.856) as compared to female (1.8264). Among the male samples, the FD values more than 1.9 have been detected as $16.66 \%$, between 1.8 and 1.9 as $77.77 \%$ and less birth defects were excluded from the study. After washing the hands thoroughly and after drying, the left hand thumb prints have been scanned with HP scanner at $600 \mathrm{dpi}$. The left hand thumb impressions have also been taken on white papers using stamp pad for the identification of fingerprint patterns along with the information of blood group and age. The FD values of scanned thumb fingerprints have been calculated using MatLab software based on box counting algorithm (Table 1) (Figure 1).

The fractal dimensions up to the fourth decimal place are found to be distinct (except for two) for different fingerprints. The FD values have ranged from 1.7284 to 1.9615 with the mean value 1.841609. We have performed t- test, Fisher $\mathrm{z}$ - test as well as Chi-square test for goodness of fit to compare the FD values among (1) males and females (2) subjects having fingerprint patterns loops and whorls (3) persons having blood groups B and $O$ and among (4) different individuals. The values of the statistics computed are summarized in the following tables (Table 2).

than 1.8 as $5.55 \%$ In females, the FD values have been detected more than 1.9 as $2.94 \%$, between 1.9 and 1.8 as $67.65 \%$ and less than 1.8 as $29.41 \%$. The t- test shows that the population means of the FD values for males and for females ought to be significantly different at $5 \%$ level of significance; whereas Fisher's z- test shows that their variance are not significantly different. Thus among males and females, there is a significant difference among the FD values but variations of FD values among individuals in males and among individuals in females are not significantly different (Figure $2 \mathrm{a} \& 2 \mathrm{~b}$ ). 


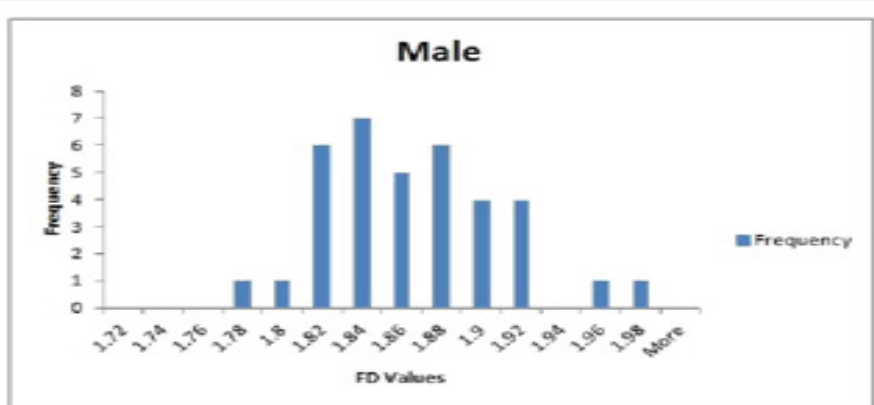

$2 a$

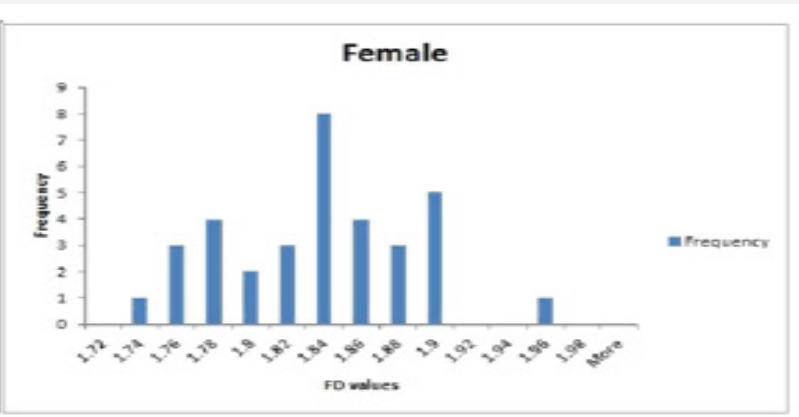

$2 \mathbf{b}$

Figure 2a \& 2b: Showing the frequency distribution of values of FD for left hand thumb fingerprints for male and female samples.

Our findings have a bearing with the findings by Kucken \& Newell [2], Rastogi \& Pillai [6] on fingerprints patterns and gender. Probably circulating sex hormones in the developing embryo might be playing a role in variation in FD values in male and female as per the report of Sanders \& Waters [7] .They have suggested a connection between finger ridge count and circulating hormone in developing embryo (Figure 3a \& 3b).

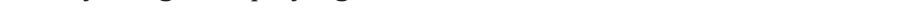
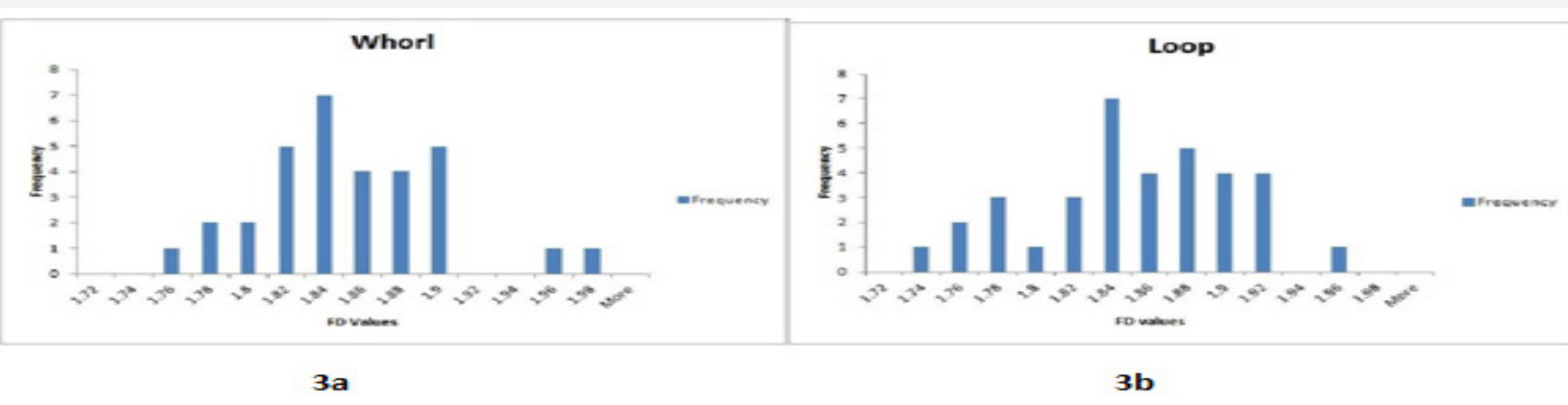

$\mathbf{3 b}$

Figure 3a \& 3b: Showing the frequency distribution of FD values for different fingerprint patterns.

In the present analysis, two main patterns loop and whorl have been detected. The arc pattern was not very clear and the frequency was observed to be less, only in six fingerprints. However Fayrouz et al. [5] reported higher frequency for loop pattern as compared to other patterns. The Fisher z-test shows that there is no significance difference in the mean as well as variance of the FD values among whorls and loops showing that they do not seem to affect the FD values (Figure 4a-4d).

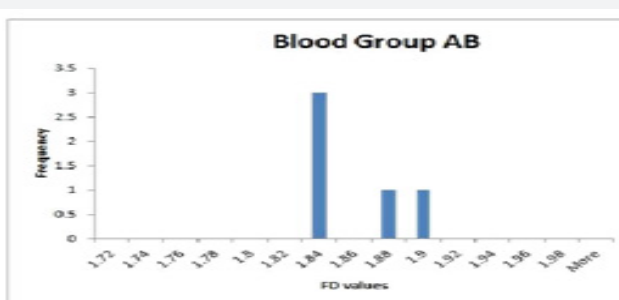

$4 a$

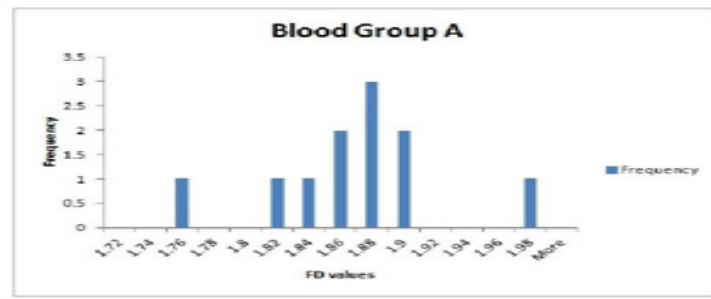

4c

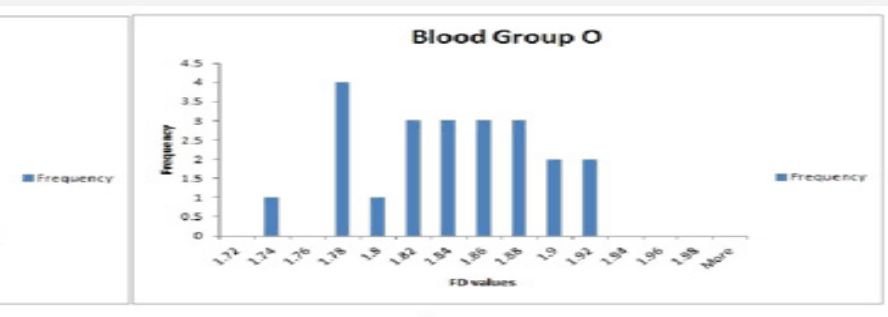

$\mathbf{4 b}$

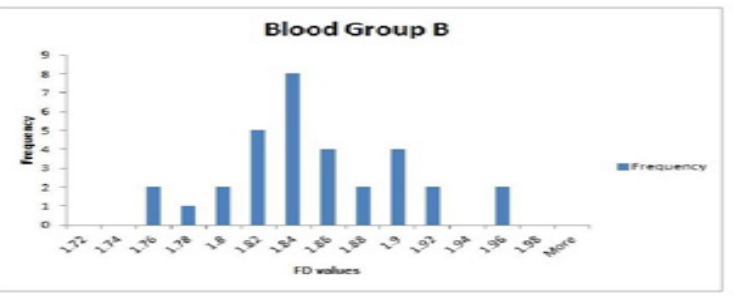

4d

Figure 4a-4d: Histograms 4 showing frequency of FD values of left hand thumb prints for individuals with $A, B, A B$ and $O$ blood groups. 
A connection between pattern of fingerprints and ABO blood groups has been suggested by Fayrouz et al. [5]. In the present work, we examine the FD values of left hand thumbprints vis a vis the blood group of individuals. In the present sample, the highest number of individuals is with blood group $B$ followed by $\mathrm{O}, \mathrm{A}$ and $\mathrm{AB}$; and the average FD values with blood groups $\mathrm{A}$ and $O$ are found to be nearly identical and calculated as 1.8723 and 1.871 respectively. This value is lower with blood group B and is 1.8346. The FD values are observed to be comparatively higher for blood group $\mathrm{A}$; and for $\mathrm{AB}$ blood group, they are observed to be lower as compared to blood groups A and B. It is inferred from the $\mathrm{t}$ - test and Fisher $\mathrm{z}$ - test that the blood groups $\mathrm{B}$ and $\mathrm{O}$ do not exerts significant effects on the FD values.

We propose a statistic $\mathrm{k}$ defined as $k=\frac{2}{N^{2}-N_{i, j=1}} \sum^{N}\left|x_{i}-x_{i}\right|$ $\mathrm{N}=$ Sample size, measure of the extent to which any two FD values values $x i$ and $x j$ for individuals $i$ and $j$ differs. This is the mean for the sample consisting of the absolute values $\left|x_{i}-x_{i}\right|$.The variance for the sample is $\sigma^{2}=\frac{2}{N^{2}-N_{i, j=1}} \sum^{N}\left|x_{i}-x_{i}\right|^{2}$ we find $\mathrm{k}=0.115707$, $\sigma^{2}=0.010913$. Then at $95 \%$ confidence limit, the population mean $\mu$ of the absolute differences between FD values for any two individuals lies in the range $\mathrm{k}-\frac{1.96 \sigma}{\sqrt{n}}, k+\frac{1.96 \sigma}{\sqrt{n}}$

where $\mathrm{n}=\mathrm{N}(\mathrm{N}-1) / 2, \mathrm{~N}=70$. Thus $\mu$ lies in the interval $(0.111541,0.119873)$ at $95 \%$ confidence level and in

$(0.110223,0.121191)$ at $1 \%$ confidence level. This shows statistically the extent to which the FD values of left hand thumbprints of any two individuals differ. Shang \& Li [10] reported the use multi-fractal characteristics of human palm prints to distinguish individuals. The mathematical aspects of fingerprints investigated so far include the topological properties of fingerprint patterns [2,11]. Indeed, fractal dimension is a topological attribute. The findings of the present note suggests that the FD value, besides being of academic interest physiologically as a distinguishing parameter, is a promising candidate to be used as an additional quantifier in the present day fingerprint identifiers based on pattern recognition.

\section{Conclusion}

1. Statistically the FD values of left hand thumb fingerprints are different for different individuals.

2. There exists statistically significant difference in FD values of left hand thumb fingerprints among males and females; though the variations of these values among males and among females are not statistically different.

3. The blood groups B and 0 as well as the fingerprints patterns loop and whorl do not exert significant effect on FD values of left hand thumb finger prints.

\section{Acknowledgement}

The results report the outcome of an interdisciplinary research project under Centre for Interdisciplinary Studies in Science and Technology (CISST), Sardar Patel University, Vallabh Vidyanagar. S. J. Bhatt is thankful to National Board for Higher Mathematics for a Visiting Professorship as well as to the DST

- PURSE Program at Sardar Patel University; whereas Jaymin Patel gratefully acknowledges support from UGC-SAP-DRS to the Department of Mathematics

\section{References}

1. Maltoni D, Cappelli R (2009) Advances in fingerprint modeling science. Image and Vision Computing 27: 258-268.

2. Kucken M, Newell A C (2005) Fingerprint formation. J Theor Biol 235(1): 71-83.

3. Pankanti S, Prabhakar S, Jain A (2002) On the individuality of fingerprints. IEEE Transaction on Pattern Analysis Machine Intellegence. 24(8): 1010-1025.

4. Jampour M, Yaghoobi M, Ashourzadsh M, Soleimani A (2010) A new fast technique for finger print identification with fractals and chaos game theory. Fractals, Complex Geometry, Pattern and Scaling in Nature and Society 18(3): 293-300.

5. Fayrouz INE, Farida, Irshad AH (2012) Relation between fingerprint and different blood groups. J Forensic Leg Med 19(1): 18-21.

6. Rastogi P, Pillai K R (2010) A study of fingerprints in relation to gender and blood group. J Indian Acad. Forensic Med. 32: 11-14.

7. Sanders G, Waters F (2001) Fingerprint asymmetry predicts within sex difference in the performance of sexually dimorphic tasks. Personality and Individual Differences 31: 1181-1191.

8. Mandelbrot B B (1982) The Fractal Geometry of Nature. In: Freeman WH (Ed.), San Francisco, USA.

9. Murray J D (2002) Mathematical Biology: I. An Introduction ( $3^{\text {rd }}$ edn), Springer.

10. Shang P, Li T (2009) Multi fractal characteristics of palm print and its extracted algorithm. Applied Mathematical Modeling 33: 4378-4387.

11. Lin CH, Chen JL, Tseng CY (2011) Optical sensor measurement and biometric-based fractal pattern classifier for finger recognition. Expert Systems with Applications 38: 5081-5089. 
This work is licensed under Creative Commons Attribution 4.0 Licens

\section{Your next submission with Juniper Publishers} will reach you the below assets

- Quality Editorial service

- Swift Peer Review

- Reprints availability

- E-prints Service

- Manuscript Podcast for convenient understanding

- Global attainment for your research

- Manuscript accessibility in different formats

( Pdf, E-pub, Full Text, Audio)

- Unceasing customer service

Track the below URL for one-step submission https://juniperpublishers.com/online-submission.php 